\title{
Biliary Copper Excretion by Hepatocyte Lysosomes in the Rat Major Excretory Pathway in Experimental Copper Overload
}

John B. Gross, Jr., Brent M. Myers, Louis J. Kost, Susan M. Kuntz, and Nicholas F. LaRusso Gastroenterology Unit and Digestive Diseases Core Center, Division of Gastroenterology and Internal Medicine, Mayo Medical School, Clinic, and Foundation, Rochester, Minnesota 55905

\begin{abstract}
We investigated the hypothesis that lysosomes are the main source of biliary copper in conditions of hepatic copper overload. We used a rat model of oral copper loading and studied the relationship between the biliary output of copper and lysosomal hydrolases. Male Sprague-Dawley rats were given tap water with or without $0.125 \%$ copper acetate for up to 36 wk. Copper loading produced a 23 -fold increase in the hepatic copper concentration and a 30-65\% increase in hepatic lysosomal enzyme activity. Acid phosphatase histochemistry showed that copper-loaded livers contained an increased number of hepatocyte lysosomes; increased copper concentration of these organelles was confirmed directly by both $x$ ray microanalysis and tissue fractionation. The copper-loaded rats showed a 16fold increase in biliary copper output and a 50-300\% increase in biliary lysosomal enzyme output. In the basal state, excretory profiles over time were similar for biliary outputs of lysosomal enzymes and copper in the copper-loaded animals but not in controls. After pharmacologic stimulation of lysosomal exocytosis, biliary outputs of copper and lysosomal hydrolases in the copper-loaded animals remained coupled: injection of colchicine or vinblastine produced an acute rise in the biliary output of both lysosomal enzymes and copper to $150-250 \%$ of baseline rates. After these same drugs, control animals showed only the expected increase in lysosomal enzyme output without a corresponding increase in copper output. We conclude that the hepatocyte responds to an increased copper load by sequestering excess copper in an increased number of lysosomes that then empty their contents directly into bile. The results provide direct evidence that exocytosis of lysosomal contents into biliary canaliculi is the major mechanism for biliary copper excretion in hepatic copper overload.
\end{abstract}

\section{Introduction}

The mammalian liver plays an integral role in copper metabolism (1-4). Normally, most of the copper absorbed from the gut is taken up by hepatocytes, at which point copper may be

Part of this work was published in abstract form (1984. Gastroenterology. 86:1322 [Abstr.]) and presented at the Annual Meeting of the American Gastroenterological Association, 1984.

Address reprint requests to Dr. Nicholas F. LaRusso, Professor of Medicine, Gastroenterology Unit, Mayo Medical School, Clinic, and Foundation, Rochester, MN 55905.

Received for publication 14 April 1988 and in revised form 12 August 1988.

J. Clin. Invest.

(c) The American Society for Clinical Investigation, Inc. $0021-9738 / 89 / 01 / 0030 / 10 \quad \$ 2.00$

Volume 83, January 1989, 30-39 incorporated into ceruloplasmin and returned to the circulation; incorporated into copper-containing enzymes, such as superoxide dismutase; stored; or excreted into bile (1-4). Biliary excretion accounts for $\sim 80 \%$ of the copper leaving the liver and is responsible for maintaining copper homeostasis (3). Reduced biliary copper excretion results in hepatic copper overload; examples include Wilson's disease $(5,6)$ and chronic cholestatic disorders such as primary biliary cirrhosis or primary sclerosing cholangitis $(7,8)$.

The mechanism by which copper is excreted into bile is not fully understood. In hepatic copper overload, previous morphologic and biochemical data have suggested that hepatocyte lysosomes act as a storage site for excess copper $(1,2,4,9,10)$. At the same time, on the basis of the work of de Duve and Wattiaux (11), we have provided evidence that hepatocyte lysosomes can release their contents directly into bile $(12,13)$. Lysosome-to-bile excretion has been documented for proteins $(12,14)$, lipoproteins (15), and iron (16). Therefore, we hypothesized that in conditions of hepatic copper overload, lysosomes are the main source of biliary copper.

To test this hypothesis, we used a rat model of hepatic copper overload to determine whether there was a relationship between the biliary output of copper and the biliary output of lysosomal markers such as lysosomal hydrolytic enzymes. We report here a close association between the biliary output of copper and lysosomal enzymes in hepatic copper overload in rats, providing direct evidence that lysosomes are the main source of biliary copper after hepatic copper loading.

\section{Methods}

24-h bile collection studies. Male Sprague-Dawley rats (Harlan Sprague-Dawley, Inc., Indianapolis, IN) were fed standard laboratory chow (Ralston Purina Co., St. Louis, MO) and either tap water $(n=9)$ or tap water containing $0.125 \%$ copper acetate $(n=15)(17)$, for up to $36 \mathrm{wk}$. Our experience with this model has shown a positive but variable relationship between the duration of copper loading and the hepatic copper content (Fig. 1). Initial body weights were 100-150 g; body weights at the time of study were $300-450 \mathrm{~g}$.

Under pentobarbital anesthesia $(50 \mathrm{mg} / \mathrm{kg}$ i.p.), the main bile duct of each rat was cannulated (PE-10 tubing), with the cannula brought out through the abdominal incision. After a 1-h recovery period, the rat was placed in a restraining cage that was then mounted onto an automatic collection apparatus. Bile was collected on ice in preweighed, metal-free vials for $24 \mathrm{~h}$, in 2-h samples. During this time, animals were given access to plain water and chow. After $24 \mathrm{~h}$, animals were killed by exsanguination. Livers were removed, trimmed of excess connective tissue, and immediately immersed in ice-cold $250 \mathrm{mM}$ sucrose buffer containing $3 \mathrm{mM}$ imidazole and $0.1 \%$ ethanol, then weighed. Cubes of liver 1-2 mm in size were fixed in Trump's formaldehyde-glutaraldehyde solution and then prepared for electron microscopy and $x$ ray microanalysis (see below). A small portion of liver was removed to a metal-free plastic vial for copper analysis. $6 \mathrm{~g}$ of the remaining liver was homogenized in $6 \mathrm{vol}$ of the same ice-cold buffer 


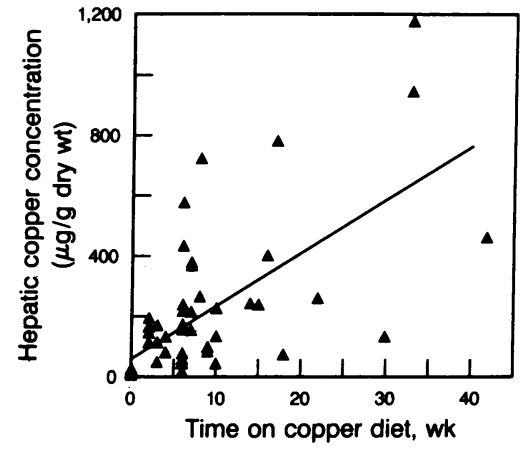

Figure 1. Hepatic copper concentration measured by atomic absorption spectroscopy in rats fed $0.125 \%$ copper acetate in drinking water ad lib. for varying periods of time. Includes data from control animals. (Linear regression equation, $y$ $=59.2+17.6 x ; r$ $=0.66, P<0.001$.)

and nuclear and postnuclear fractions were separated by cold centrifugation at $1,200 \mathrm{~g}$ for $10 \mathrm{~min}$ as previously described (12). Bile samples were weighed and 2 -h $\mathrm{h}$ volumes were determined, assuming a density of $1 \mathrm{~g} / \mathrm{ml}$. Liver homogenates and bile were then frozen at $-70^{\circ} \mathrm{C}$ for up to 2 wk.

Acute pharmacologic perturbation of hepatic lysosomes. Another group of similar rats was raised in the same way. 8-h bile collections were performed in 14 copper-loaded and 15 control rats. The procedure was as above, except that an additional catheter (PE-50) was maintained in a femoral vein and pentobarbital anesthesia was maintained for the duration of the study period. Bile was collected on ice in 30-min samples.

Our previous studies had shown that acute administration of colchicine or vinblastine caused a large, transient elevation in the biliary output of lysosomal enzymes in rats (18). Therefore, after an equilibration period of $4 \mathrm{~h}, 5 \mu \mathrm{mol} / \mathrm{kg}$ colchicine (Sigma Chemical Co.); 5 $\mu \mathrm{mol} / \mathrm{kg}$ lumicolchicine; $10 \mathrm{mg} / \mathrm{kg}$ vinblastine (Velban; Eli Lilly and Co., Indianapolis, IN); or an equivalent volume of saline was injected as an intravenous bolus. Bile collection was then continued for $4 \mathrm{~h}$. Lumicolchicine was prepared as described (18). Animals were killed by exsanguination. Livers were processed and analyses of liver and bile were performed as described above.

Hepatic subcellular fractionation studies. A third group of rats was raised as above. Copper loading was carried out for periods varying up to $2 \mathrm{mo}$. Animals were killed by exsanguination and the livers were removed and homogenized as described above. Latency of lysosomal enzyme activity in the postnuclear supernate was used as an index of lysosomal integrity, by comparing enzyme activities before and after addition of $0.1 \%$ Triton X-100 to the assay mix. For homogenates with latencies $>78 \%$, the postnuclear supernate from some experiments was then further separated into mitochondrial, lysosomal, microsomal, and cytosolic fractions by differential centrifugation (19); each subcellular fraction was then assayed for the three lysosomal hydrolases, copper, and the following marker enzymes: malate dehydrogenase $(\mathrm{MDH})^{1}(20)$, microsomal esterase (21), and lactate dehydrogenase (LDH) (22), markers for the mitochondrial, microsomal, and cytosolic fractions, respectively.

Biochemical analyses. Copper analysis of liver pieces and bile was carried out using flameless atomic absorption spectrophotometry (model 5000; Perkin-Elmer Corp., Norwalk, CT) (23). Liver homogenates and bile were analyzed for the three lysosomal enzymes $N$-acetyl- $\beta$-glucosaminidase ( $\beta$-NAG, EC 2.3.1.30), $\beta$-glucuronidase $(\beta$ GLU, EC 3.2.1.31), and $\beta$-galactosidase ( $\beta$-GAL, EC 3.2.1.23); the plasma membrane enzyme alkaline phosphodiesterase-I (APD-I); the cytosolic marker enzyme LDH; the mitochondrial marker enzyme $\mathrm{MDH}$; and total protein. Lysosomal enzymes were assayed by an es-

1. Abbreviations used in this paper: APD-I, alkaline phosphodiesterase-I; $\beta$-NAG, $N$-acetyl- $\beta$-glucosaminidase; $\beta$-GLU, $\beta$-glucuronidase; $\beta$-GAL, $\beta$-galactosidase; EM, electron micrograph; LDH, lactate dehydrogenase; $\mathrm{MDH}$, malate dehydrogenase. tablished fluorometric method using 4-methyl-umbelliferone substrates (24), previously validated in our laboratory for liver and bile (12). APD-I was assayed spectrophotometrically (25). Total protein was determined by the Lowry method (26).

$X$ ray microanalysis. Specimens for transmission electron microscopy (EM) were processed in the usual manner, according to previously published methods (16). Energy-dispersive $\mathrm{x}$ ray microanalysis of copper was performed on unstained specimens on titanium grids, in a Philips 400 HTG transmission electron microscope equipped with a lithium drifted detector (resolution $146 \mathrm{eV}$ ), attached to a Micro-x 7000 analyzer. Accelerating voltage was $60 \mathrm{kV}$, beam current was 40 $\mu \mathrm{A}$, and beam spot was $500 \mathrm{~nm}$. Live counting time was $180 \mathrm{~s}$ per measurement. Measurements were made over lysosome-like structures, over adjacent cytoplasm, and over the embedding medium.

Histochemistry. To have a specific morphologic marker for lysosomes, we used acid phosphatase histochemistry (27) in thin slices of liver immersed for $3 \mathrm{~h}$ in $2 \%$ formaldehyde (prepared from paraformaldehyde), $2.5 \%$ glutaraldehyde, in $0.1 \mathrm{M}$ cacodylate buffer, $\mathrm{pH} 7.5$, $0.025 \% \mathrm{CaCl}_{2}, 5 \%$ sucrose. After fixation, tissue was rinsed twice with buffer and then kept overnight in cold buffer before nonfrozen sections were prepared with a vibratome. Vibratome sections $30 \mu \mathrm{m}$ thick were collected in cold $7.5 \%$ sucrose. Sections were incubated at $37^{\circ} \mathrm{C}$ for 30 min in incubation medium that contained $25 \mathrm{mg}$ cytidine $5^{\prime}$-monophosphate, disodium salt, $12 \mathrm{ml}$ distilled water, $10 \mathrm{ml} 0.05 \mathrm{M}$ acetate buffer, $\mathrm{pH} 5.0$, and $3 \mathrm{ml} 1 \%$ lead nitrate, $5 \%$ sucrose. Incubation medium was used after it developed a slight precipitation, after incubation at $37^{\circ} \mathrm{C}$ for $30 \mathrm{~min}$. It was then filtered and used immediately. Sections were rinsed in $7.5 \%$ sucrose, treated with dilute ammonium sulfide, rinsed in $7.5 \%$ sucrose and mounted in glycerol gelatin for light microscopy. For transmission EM, sections were postfixed in $1 \%$ osmium tetroxide in $0.1 \mathrm{M}$ cacodylate buffer with $5 \%$ sucrose, rinsed several times in buffer, dehydrated in a graded series of ethanol, treated with propylene oxide, and embedded in Spurr's low-viscosity epoxy resin (28). Thin sections were cut on an ultramicrotome (Ultracut $E$; Reichert Scientific Instruments, Buffalo, NY) with a diamond knife. Sections were stained in Reynolds lead citrate and uranyl acetate for 5 min each and observed with a Philips 201 electron microscope.

Data analysis. Group comparisons of liver measurements and cumulative bile measurements were made with a two-sample independent $t$ test, with conversion to $\log$ scale where necessary to achieve similar variances. The relationship between the 2-h biliary outputs of lysosomal enzymes and copper were analyzed by linear regression analysis, with conversion to $\log$ scale where variances dictated. Analyses were performed using the CLINFO Data Management and Analysis System (Bolt, Baranek, and Newman).

\section{Results}

Measurements on liver. Table I summarizes the effect of copper loading on body weight, liver weight, and biochemical measurements in liver. The two groups were not significantly different with regard to final body weight, liver weight, total hepatic protein, or hepatic content of the plasma membrane marker APD-I, the cytosolic marker enzyme LDH, or the mitochondrial marker enzyme MDH. The success of the copperfeeding method in copper loading was demonstrated by a 23fold increase in hepatic copper content in the copper-fed group relative to controls $(341 \pm 90$ vs. $15.1 \pm 0.6 \mu \mathrm{g} / \mathrm{g}$ dry weight, means \pm SE). Copper loading produced a significant increase in the activity of two lysosomal enzymes in liver (Table I).

Liver morphology. Light micrographs of liver sections stained by histochemistry for acid phosphatase showed a marked increase in the number and density of lysosomes in copper-loaded animals relative to controls (Fig. 2). Transmission EM of liver sections from control and copper-loaded rats showed general preservation of organelle morphology (Fig. 3). 
Table I. Body Weight, Liver Weight, and Biochemical Measurements in Liver in Control and Copper-fed Rats (Means \pm SE)

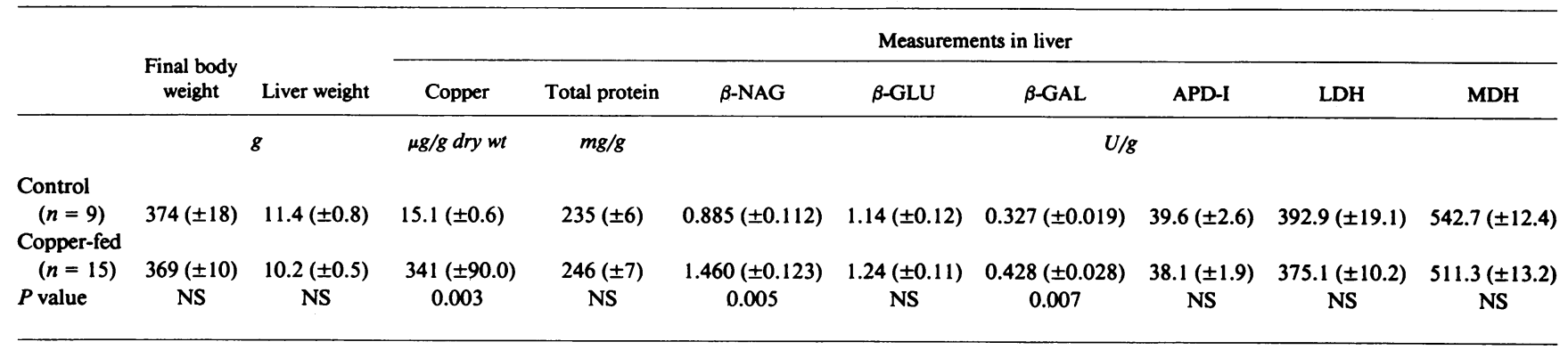

We noted that the increased numbers of lysosome-like structures in the copper-loaded animals were mainly in the pericanalicular areas. Comparison of standard EMs with EMs stained for acid phosphatase confirmed that these pericanalicular structures were lysosomes (Fig. 3).

$\mathrm{X}$ ray microanalysis confirmed that the structures identified as lysosomes by acid phosphatase histochemistry contained high concentrations of copper (Fig. 4). Over lysosomes, a major peak was seen at $8.041 \mathrm{KeV}$ and a lesser peak at 1.04 $\mathrm{KeV}$, the expected peaks for copper; neighboring cytoplasm showed no such peaks. A prominent sulfur peak $(2.3 \mathrm{KeV})$ accompanied the copper peaks, probably representing the sulfhydryl groups of copper-binding proteins. Control animals showed no copper peaks over either lysosomes or cytoplasm because the amounts of copper normally present in liver are below the detection limits of this technique (Fig. 4).

Subcellular hepatic copper distribution. The subcellular distribution of copper was determined by differential centrifugation in a normal rat liver and a liver from a rat loaded with copper for 6 wk as described in Methods. The concentrations of copper were $13 \mu \mathrm{g} / \mathrm{g}$ dry weight in the normal rat liver and $241 \mu \mathrm{g} / \mathrm{g}$ dry weight in the copper-loaded rat. In the normal rat, the majority of copper was recovered in the cytosolic or $\mathrm{S}$-fraction as demonstrated by the similarity in the distribution patterns of copper and LDH (Fig. 5). In contrast, in the copper-loaded rat, the subcellular distribution of copper was virtually identical to that of the lysosomal marker enzyme, $\beta$-NAG, with a high peak in the lysosomal or L-fraction. The distribution patterns for all other marker enzymes were similar in the control and copper-loaded rats.

Latency of lysosomal enzymes in rat liver. There was a decrease in the mean latent activities of copper-loaded rats compared with controls $(71.5 \pm 2.5 \%$ vs. $84.7 \pm 1.6 \%, P<0.06)$. Furthermore, a significant inverse relationship $(r=-0.80, P$ $<0.0001$ ) between hepatic copper concentration and lysosomal latency was found (Fig. 6).

Cumulative biliary excretion of lysosomal enzymes and copper. Table II summarizes the cumulative biliary outputs of copper, total protein, and enzymes over the 24-h study period. There was no significant difference between the two groups in total bile output or in the output of total protein or APD-I, the plasma membrane marker enzyme. Hepatic copper loading produced a significant increase in biliary copper excretion relative to controls $(15.8 \pm 1.8$ vs. $1.00 \pm 0.09 \mu \mathrm{g} / 24 \mathrm{~h} ; P<0.001)$. This was accompanied by higher total outputs for all three lysosomal enzymes relative to controls: $\beta$-NAG, $256.7 \pm 73.2$ vs. $79.1 \pm 28.7 ; \beta$-GLU, $127.6 \pm 29.2$ vs. $53.5 \pm 8.2 ; \beta$-GAL,
$75.4 \pm 18.4$ vs. $52.8 \pm 19.2 \mathrm{mU} / 24 \mathrm{~h}$. These differences were statistically significant for $\beta-N A G$ and $\beta-$ GLU.

In vitro bile-mixing experiments from three randomly selected pairs of control and copper-loaded rats demonstrated that bile from the copper-loaded animals did not increase the lysosomal enzyme activity of control bile. We concluded that the higher lysosomal enzyme activities in the bile of copperloaded animals were not due to increased levels of biliary copper.

Relationship between biliary excretion of lysosomal enzymes and copper. We were interested to know whether variations in the biliary outputs of copper and lysosomal enzymes in the copper-loaded rats occurred simultaneously. Therefore, we plotted the output rates over the collection period for each rat for copper, lysosomal enzymes, and APD-I. The output rates were expressed as a percentage of the initial rate, to allow for the differences in the absolute output rates among animals.

The biliary output rates for the three lysosomal enzymes varied in a coordinate fashion with each other in both the copper-loaded and control animals (data not shown), confirming our previous observations (12). The biliary output of copper likewise varied in a coordinate manner with the lysosomal enzyme outputs in the copper-loaded animals, but not in the controls (Fig. 7).

The 2-h biliary outputs of copper were compared by regression analysis with the 2-h outputs of each of the three lysosomal enzymes and the plasma membrane marker enzyme (Table III). Copper-loaded rats showed median correlation coefficients ( $r$ values) of $0.88,0.80$, and 0.76 for copper versus $\beta$-NAG, $\beta$-GLU, and $\beta-G A L$, respectively. In contrast, the corresponding values for control rats were $0.54,0.39$, and 0.50 .

The correlation coefficients for the biliary output of copper versus the plasma membrane enzyme APD-I was similar in copper-loaded and control rats $(0.57$ vs. 0.51$)$, and of the same magnitude as the copper-lysosomal enzyme correlations in the control rats. As expected from our previous observations (12), the correlation coefficients for the biliary outputs of the three pairs of lysosomal enzymes were high in both the copperloaded and control group (Table III). The correlations between lysosomal marker enzymes and APD-I were low in both groups.

Effects of acute pharmacologic perturbation of hepatic lysosomes. In both copper-loaded $(n=14)$ and control $(n=15)$ animals, injection of either colchicine or vinblastine produced an acute rise in the biliary output of all three lysosomal enzymes. The rate of excretion of $\beta$-glucuronidase rose to $150-300 \%$ of the baseline rate $1 \mathrm{~h}$ after injection (Fig. 8), with 



Figure 2. Light micrographs of rat liver stained for lysosomal acid phosphatase by histochemical technique. $(A)$ Liver from control rat. (B) Liver from a rat after $12 \mathrm{wk}$ of copper loading. Note increased number and density of lysosomes in the copper-loaded liver. $\times 345$.

comparable increases in both copper-loaded and control groups. Rate increases for the other two lysosomal enzymes were similar, duplicating our previous observations $(16,18)$. Neither saline (Fig. 8) nor lumicolchicine (data not shown) affected biliary lysosomal enzyme output.

There was a prompt rise in biliary copper output in copper-loaded animals after either colchicine or vinblastine injection (Fig. 8). The peak output in copper-loaded animals occurred at $1 \mathrm{~h}$ after injection, simultaneous with the peak lysosomal enzyme output, reaching $150 \%$ of the baseline copper output for each agent. In contrast, the control animals showed no change in biliary copper output after colchicine or vinblastine.
Bile flow, biliary total protein output, and biliary APD-I output were unaffected by injection of saline, colchicine, or vinblastine in either control or copper-loaded animals. Lumicolchicine had no effect on the output of any of the measured biliary constituents.

\section{Discussion}

The major conclusion of our experiments in this rat model of dietary hepatic copper loading is that hepatocyte lysosomes are the main source of biliary copper. Although this phenomenon has been assumed by previous authors (2-4), ours are the first experimental data to support this conclusion directly. We base 

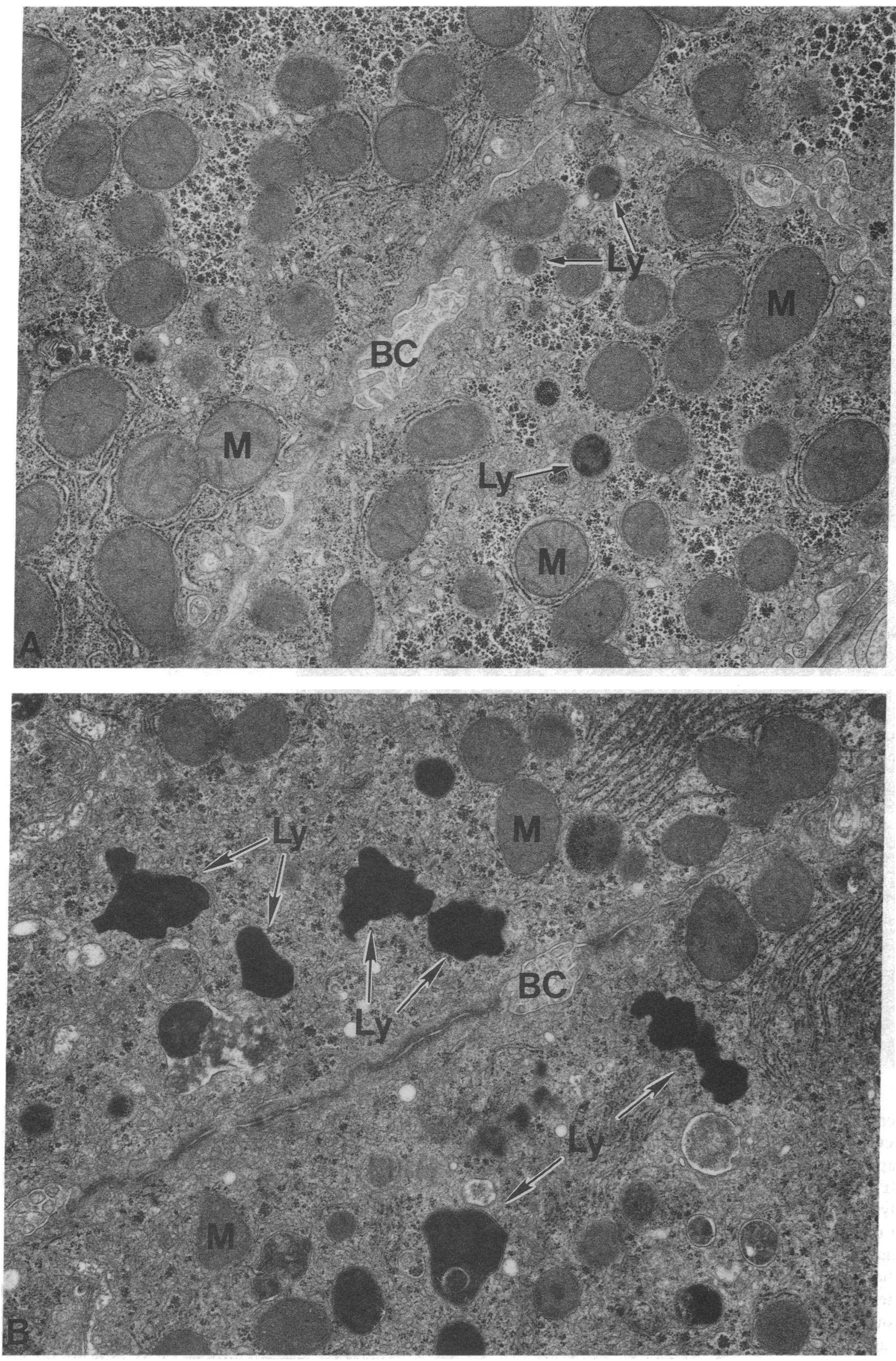

Figure 3. Transmission electron micrographs of livers from copperloaded and control rats, with and without histochemical staining for acid phosphatase. $(A)$ Control liver, unstained. $(B)$ Copper-loaded liver, unstained. $(C)$ Control liver, stained for acid phosphatase. $(D)$ Copper-loaded liver, stained for acid phosphatase. Note difference in size and shape between control and copper-loaded lysosomes, as well as the pericanalicular clustering of lysosomes in the copper-loaded liver. Ly, lysosome; M, mitochondria; BC, bile canaliculus. Final magnification, $\times 25,000$. 

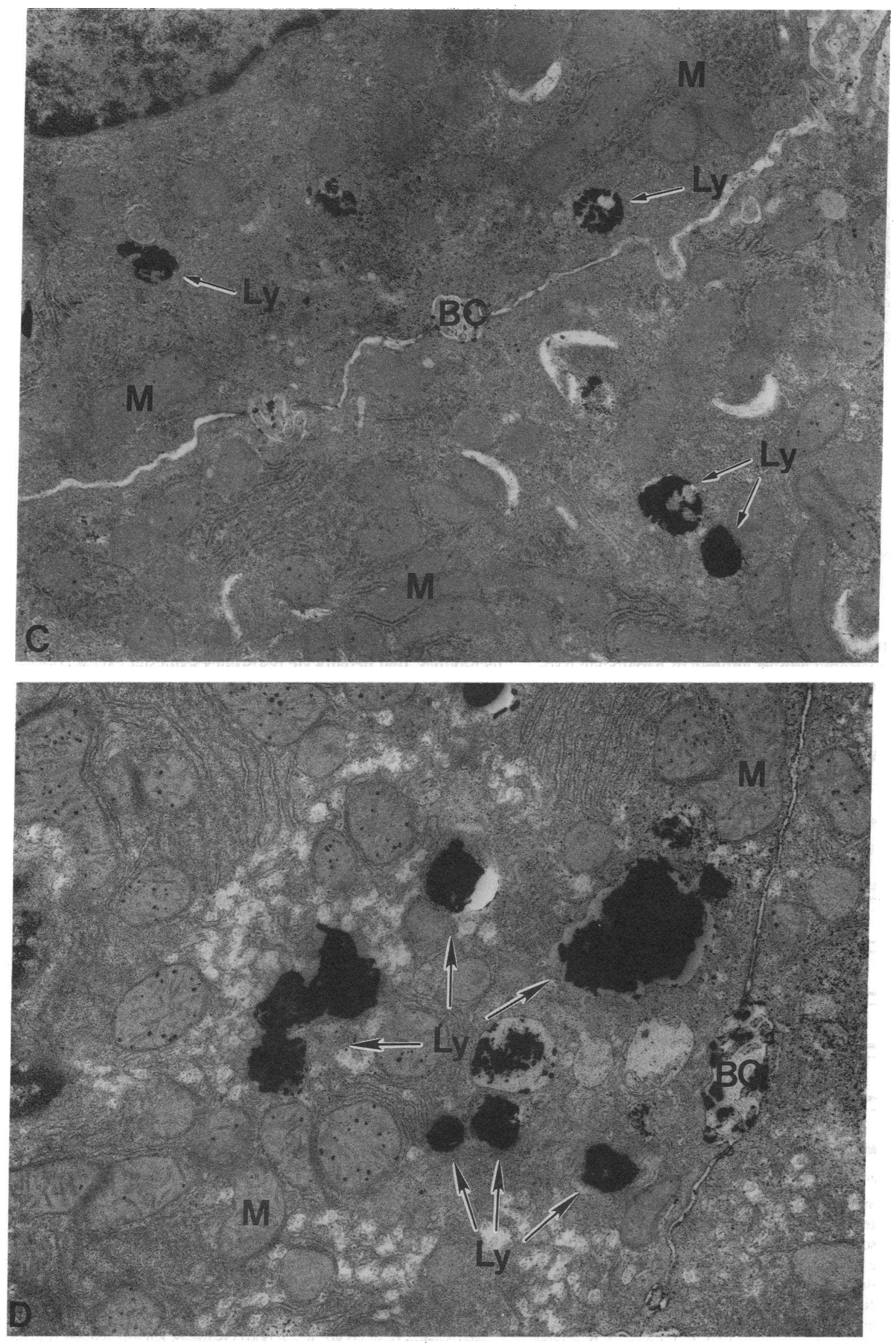

Figure 3 (Continued) 

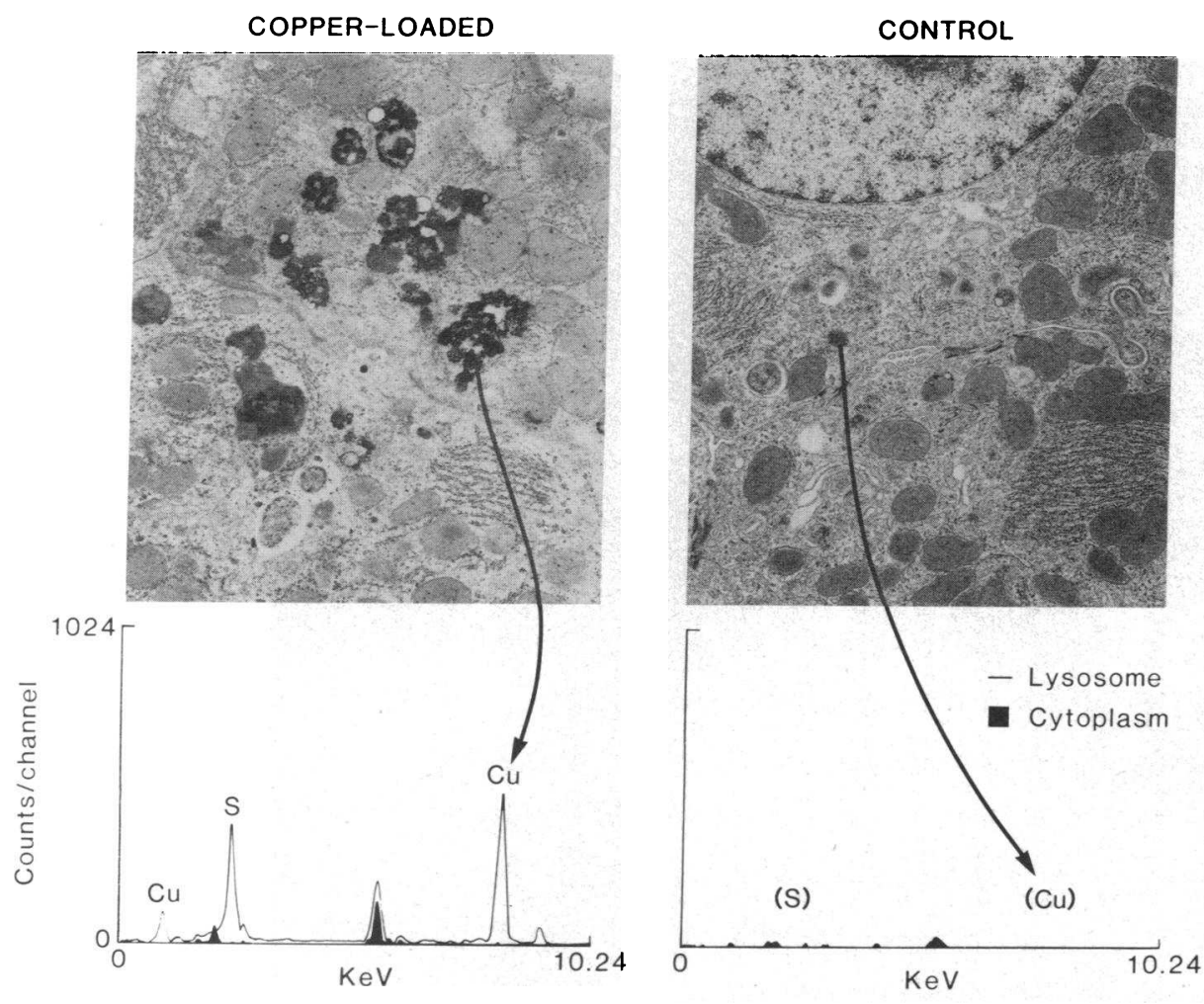

Figure 4. Results of $x$ ray microanalysis performed on electron micrographs of livers from copper-loaded and control rats. Energy emission spectra for each animal show the differences between lysosomes (line) and neighboring cytoplasm (shaded). Peaks at 8.041 and $1.04 \mathrm{keV}$ are characteristic of copper $(\mathrm{Cu})$; peak at $2.3 \mathrm{keV}$ is characteristic of sulfur (S), and is due to the presence of copper-binding proteins with sulfhydryl groups. Peaks for copper and sulfur are present over lysosomes in copper-loaded but not in control rats. this conclusion on the observations that, first, the excess hepatic copper is sequestered almost entirely in hepatocyte lysosomes and, second, the biliary outputs of copper and lysosomal enzymes are highly correlated both in the basal state and after administration of agents known to acutely enhance biliary emptying of lysosomes.

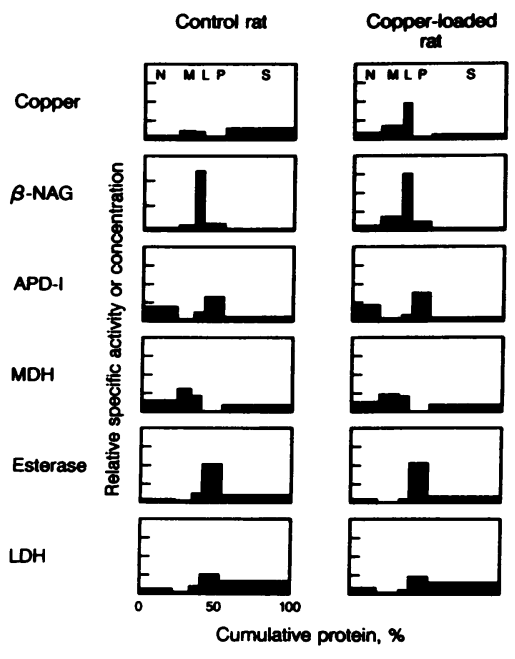

Figure 5. Subcellular fractionation profiles for marker enzymes and copper in control and copper-loaded rat. Fractions (N, M, L, P, $S)$ are represented on the ordinate by the relative specific activity of the constituent (percentage of total activity/ percentage of total protein) and cumulatively on the abscissa by its percentage protein. In the control rat, the distribution pattern of copper resembled the distribution pattern of

LDH, the cytosolic marker enzyme. In contrast, after copper loading, the distribution pattern of copper resembled the distribution pattern of $\beta$-NAG, the lysosomal marker enzyme. Recovery of measured constituents relative to the homogenate averaged 101 and $97 \%$ in the control and copper-loaded rats, respectively; this was calculated by summing the activities in the five fractions for a given enzyme and dividing this number by the total activity for the same enzyme in the homogenate. $\mathrm{N}$, nuclear; $\mathrm{M}$, mitochondrial; L, lysosomal; P, microsomal; S, cytosolic.
Our observation, using both biochemical and morphologic techniques, that hepatocyte lysosomes sequester excess copper rigorously extends the previous tentative conclusions of other investigators. McNary (29) found copper granules in the hepatocytes of copper-loaded rats that had the ultrastructural characteristics of lysosomes; however, cytochemical techniques such as those used in this study were not used to establish directly the lysosomal nature of these organelles. Goldfischer (30) found acid phosphatase activity in hepatocyte copper particles in a rat model of copper overload; however, neither tissue fractionation nor $x$ ray microanalysis was used to prove that the lysosomes contained excess copper.

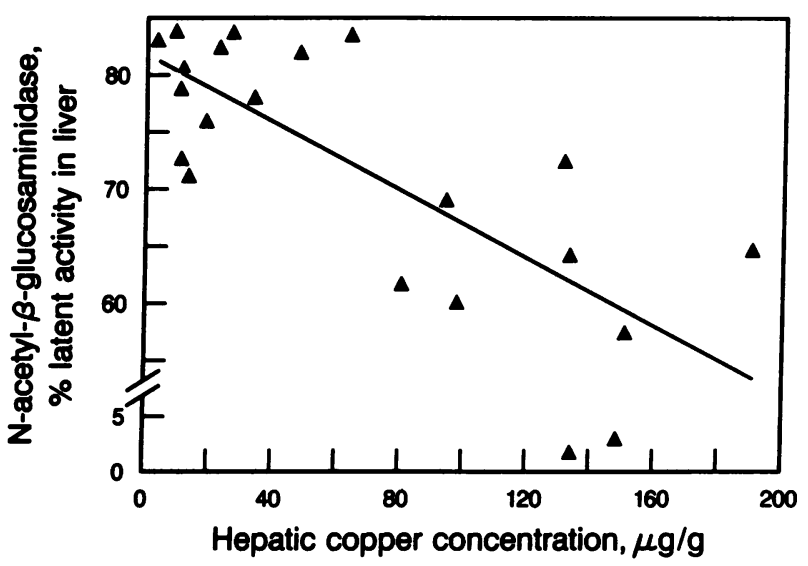

Figure 6. Relationship between hepatic copper concentration and latent activity of $N$-acetyl- $\beta$-glucosaminidase in rat liver. Latency was determined as described in Methods. There was a significant inverse relationship $(r=-0.80, P<0.0001)$ between hepatic copper concentration and lysosomal latency. 
Table II. Cumulative 24-h Outputs into Bile in Control and Copper-Loaded Rats, per Gram of Liver (Means $\pm S E$ )

\begin{tabular}{|c|c|c|c|c|c|c|c|}
\hline & \multirow[b]{2}{*}{ Bile volume } & \multirow[b]{2}{*}{ Copper } & \multirow[b]{2}{*}{ Total protein } & \multicolumn{4}{|c|}{ Lysosomal enzymes } \\
\hline & & & & $\beta$-NAG & $\beta-G L U$ & $\beta-G A L$ & APD-I \\
\hline & $m l$ & $\mu g$ & $m g$ & \multicolumn{4}{|c|}{$m U$} \\
\hline Control $(n=9)$ & $1.98( \pm .09)$ & $1.00( \pm .09)$ & $10.7( \pm 4.6)$ & $79.1( \pm 28.7)$ & $53.5( \pm 8.2)$ & $52.8( \pm 19.2)$ & $92.2( \pm 20.4)$ \\
\hline Copper-loaded $(n=15)$ & $2.06( \pm .10)$ & $15.84( \pm 1.79)$ & $12.2( \pm 3.7)$ & $256.7( \pm 73.2)$ & $127.6( \pm 29.2)$ & $75.4( \pm 18.4)$ & $73.6( \pm 15.8)$ \\
\hline$P$ value & NS & $<0.001$ & NS & $<0.05$ & $<0.05$ & NS & NS \\
\hline
\end{tabular}

Hazelrig and co-workers (31) proposed a three-compartment model to explain the kinetics of radiocopper metabolism in the rat hepatocyte. Owen (1) has proposed that the lysosome is the anatomic equivalent of the excretory and storage compartments. Sternlieb also hypothesized that lysosomes might be the source of the copper excreted into bile (10). He noted that hepatocyte lysosomes could normally release their enzymatic contents directly into biliary canaliculi by exocytosis $(11,12)$ and observed in a single patient with Wilson's disease, that the low specific activity in bile of previously administered ${ }^{64} \mathrm{Cu}$ matched that of the lysosomal fraction of a homogenized liver sample (10).

Copper loading produces an increase in the number of hepatocyte lysosomes. The increase in the total activities of lysosomal enzymes in the copper-loaded livers relative to the controls paralleled the visible increase in the numbers of lysosomes. This induction effect has been observed in response to an excess of other substances sequestered in lysosomes, including iron $(11,13,16)$, and appears to be organelle specific, since no changes were observed in the activities of mitochondrial, plasma membrane, or cytosolic marker enzymes.

Although there is no doubt that the hepatocyte responds to a copper load by sequestering excess copper in an increased number of lysosomes, the notion that there is also direct excretion of copper into bile has remained speculative. In this study, the measurements of lysosomal enzymes and copper in bile provide evidence that copper-laden hepatocyte lysosomes

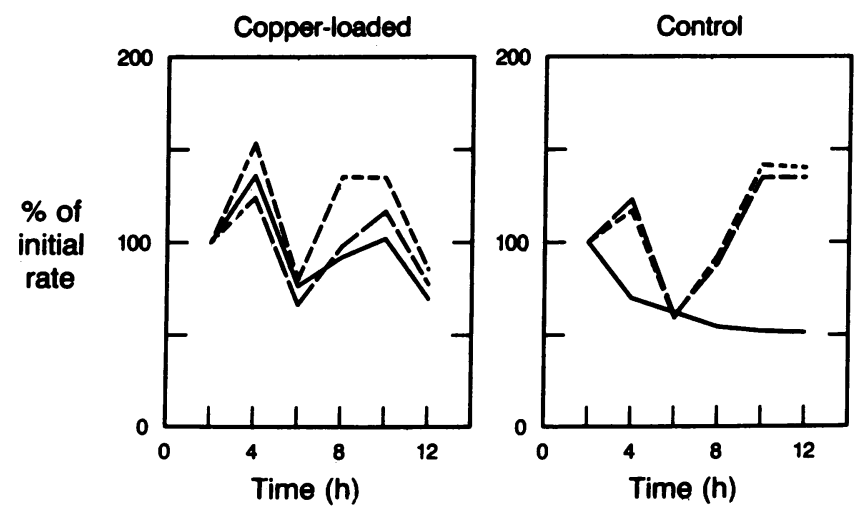

Figure 7. Biliary output profiles of the lysosomal enzymes $N$-acetyl$\beta$-glucosaminidase ( $\beta$-NAG) and $\beta$-galactosidase $(\beta-\mathrm{GAL})$ and of copper in copper-loaded and control rats. Rates were determined from consecutive 2-h samples of bile and are expressed as a percentage of the initial rate. Note the similarity of the curves in the copper-loaded animal. - - , copper; - - - $\beta$-NAG; and - - , $\beta$-GAL. do indeed excrete copper directly into bile. First, an increase in cumulative biliary copper excretion in copper-loaded rats was associated with an increased cumulative excretion of lysosomal enzymes into bile. Second, the excretory pattern of copper into the bile of copper-loaded rats showed a high correlation in time with the excretory pattern into bile of lysosomal enzymes. There was no such correlation in the control rats, nor was there a copper-enzyme correlation in the copper-loaded rats for a nonlysosomal enzyme (APD-I). Finally, when lysosomes were stimulated by colchicine or vinblastine to release their contents into bile, a simultaneous increase in the rate of appearance of copper and lysosomal enzymes occurred in copper-loaded animals, but not in controls. This suggests a common origin for copper and lysosomal enzymes in copperloaded livers that is not present under normal conditions. When the hepatocyte contains a normal amount of copper, lysosomal delivery of copper to bile is apparently less important; indeed, biliary copper excretion probably proceeds by a different mechanism.

The 16-fold increase in the 24-h biliary output of copper in the copper-loaded animals (Table II) was comparable to the 23-fold increase in total hepatic copper (Table I), suggesting that hepatocyte lysosomes release their contents into bile at about the same rate as in normal rats. Whether there is any actual stimulus to the stressed lysosomal system to promote lysosomal exocytosis remains unknown. However, the increase of roughly $50 \%$ in total hepatic lysosomal enzyme activ-

Table III. Correlations (r Values) among 2-h Biliary Outputs over 24 h of Copper, Three Lysosomal Enzymes, and a Plasma Membrane Enzyme

\begin{tabular}{lcccc}
\hline & $\begin{array}{c}\text { Copper-loaded } \\
\text { rats }(n=15)\end{array}$ & $P$ value & $\begin{array}{c}\text { Control rats } \\
(n=9)\end{array}$ & $P$ value \\
\hline Copper vs. $\beta$-NAG & $0.88^{*}$ & 0.001 & 0.54 & NS \\
Copper vs. $\beta$-GLU & 0.80 & 0.002 & 0.39 & NS \\
Copper vs. $\beta$-GAL & 0.76 & 0.005 & 0.50 & NS \\
Copper vs. APD I & 0.57 & NS & 0.51 & NS \\
$\beta$-NAG vs. $\beta$-GLU & 0.96 & 0.0001 & 0.96 & 0.0001 \\
$\beta$-NAG vs. $\beta$-GAL & 0.91 & 0.001 & 0.95 & 0.0001 \\
$\beta$-GLU vs. $\beta$-GAL & 0.84 & 0.001 & 0.97 & 0.0001 \\
$\beta$-NAG vs. APD I & 0.54 & NS & 0.50 & NS \\
$\beta$-GLU vs. APD I & 0.47 & NS & 0.27 & NS \\
$\beta$-GAL vs. APD I & 0.39 & NS & 0.41 & NS \\
& & & & \\
\hline
\end{tabular}

Correlation coefficient of biliary output with time of first constituent vs. the second as determined for each animal.

* Median values for correlation coefficients $(r)$. 


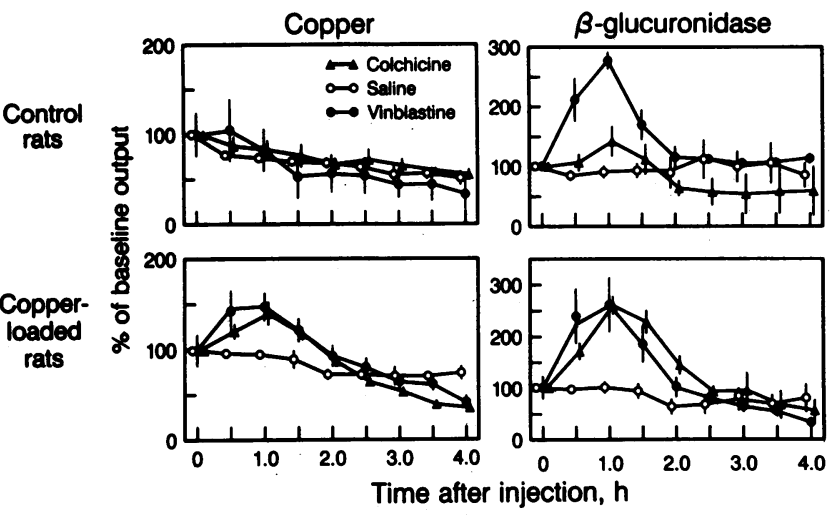

Figure 8. Biliary outputs of $\beta$-glucuronidase and copper in copperloaded and control rats injected with saline, colchicine, or vinblastine at time 0 . Outputs are plotted as a percentage of the output in the 30 min before injection. Colchicine or vinblastine produces acute increases in both lysosomal enzyme and copper output in copperloaded animals, but control animals show only the expected increase in lysosomal enzyme output without a corresponding increase in copper (means $\pm \mathrm{SE}$ ).

ity also approximated the doubling of the 24-h biliary output of lysosomal enzymes in copper-loaded animals. This observation also suggests that copper-loaded lysosomes release their contents into bile at about the same rate as do normal lysosomes.

Copper overload was achieved in these studies by increasing copper intake rather than decreasing biliary copper excretion. Our model presumably leaves the canaliculus and the hepatocyte excretory apparatus intact. Decreased biliary excretion is mainly responsible for the hepatic copper accumulation that occurs in primary copper toxicosis (Wilson's disease) and in such chronic cholestatic disorders as primary biliary cirrhosis and primary sclerosing cholangitis $(7,8)$. Copper accumulation in these diseases is detrimental to cell function, particularly in Wilson's disease $(4,32)$. We cannot conclude from our studies whether pharmacologic manipulation of the lysosomal system with agents that promote lysosomal exocytosis at the canaliculus would increase biliary copper excretion in these diseases featuring an excretory block. The direct demonstration by results reported here that exocytosis of hepatocyte lysosomal contents into biliary canaliculi is the major route of excretion of excess hepatic copper provides a firm theoretical basis for performing studies aimed at assessing whether chronic pharmacologic manipulation of this lysosomal excretory pathway may be clinically useful in such diseases. If biliary copper excretion could be accelerated, such a therapeutic approach could potentially benefit patients with hepatic copper accumulation because it has been demonstrated that there is negligible reabsorption of biliary copper in the gut $(1,33)$.

\section{Acknowledgments}

This work was supported by the Mayo Foundation and by National Institutes of Health grants DK-24031, DK-34988, and RR-585.

\section{References}

1. Owen, C. A., Jr. 1982. Physiological aspects of copper. Noyes Publications, Park Ridge, NJ. 105-158.
2. Mason, K. E. 1979. A conspectus of research on copper metabolism and requirements of man. J. Nutr. 109:1979-2066.

3. Evans, G. W. 1973. Copper homeostasis in the mammalian system. Physiol. Rev. 53:535-570.

4. Sternlieb, I. 1980. Copper and the liver. Gastroenterology 78:1615-1628.

5. O'Reilly, S., P. M. Weber, M. Oswald, and L. Shipley. 1971. Abnormalities of the physiology of copper in Wilson's disease. Arch. Neurol. 25:28-32.

6. Frommer, D. J. 1974. Defective biliary excretion of copper in Wilson's disease. Gut. 15:125-129.

7. Hunt, H. A., R. M. Parr, D. M. Taylor, and N. G. Trott. 1963. Relation between cirrhosis and trace metal content of liver with special reference to primary biliary cirrhosis and copper. Br. Med. J. 2:14981501.

8. Gross, J. B., Jr., J. Ludwig, R. H. Wiesner, J. T. McCall, and N. F. LaRusso. 1985. Abnormalities in tests of copper metabolism in primary sclerosing cholangitis. Gastroenterology. 89:272-278.

9. Goldfischer, S. 1965. The localization of copper in the pericanalicular granules (lysosomes) of liver in Wilson's disease (hepatolenticular degeneration). Am. J. Pathol. 46:977-983.

10. Sternlieb, I., C. J. A. van den Hamer, A. G. Morell, S. Alpert, G. Gregoriadis, and I. H. Scheinberg. 1973. Lysosomal defect of hepatic copper excretion in Wilson's disease (hepatolenticular degeneration). Gastroenterology. 64:99-105.

11. de Duve, C., and R. Wattiaux. 1966. Functions of lysosomes. Annu. Rev. Physiol. 28:435-492.

12. LaRusso, N. F., and S. Fowler. 1979. Coordinate secretion of acid hydrolases in rat bile: hepatocyte exocytosis of lysosomal protein? J. Clin. Invest. 64:948-954.

13. LaRusso, N. F., L. J. Kost, J. A. Carter, and S. S. Barham. 1982. Triton WR-1339, a lysosomotropic compound, is excreted into bile and alters the biliary excretion of lysosomal enzymes and lipids. Hepatology (Baltimore.). 2:209-215.

14. Coffey, R. J., L. J. Kost, R. M. Lyons, H. L. Moses, and N. F. LaRusso. 1987. Hepatic processing of transforming growth factor $\beta$ in the rat. Uptake, metabolism, and biliary excretion. J. Clin. Invest. 80:750-757.

15. Sewell, R. B., S. J. Mao, T. Kawamoto, and N. F. LaRusso. 1983. Apoproteins of high, low, and very low density lipoproteins in human bile. J. Lipid Res. 24:391-401.

16. LeSage, G. D., L. J. Kost, S. S. Barham, and N. F. LaRusso. 1986. Biliary excretion of iron from hepatocyte lysosomes in the rat. A major excretory pathway in experimental iron overload. J. Clin. Invest. 77:90-97.

17. Owen, C. A., Jr., and J. B. Hazelrig. 1968. Copper deficiency and copper toxicity in the rat. Am. J. Physiol. 215:334-338.

18. Sewell, R. B., S. S. Barham, A. R. Zinsmeister, and N. F. LaRusso. 1984. Microtubule modulation of biliary excretion of endogenous and exogenous hepatic lysosomal constituents. Am. J. Physiol. 246:G8-G15.

19. de Duve, C., B. C. Pressman, R. Gianetto, R. Wattiaux, and F. Appelmans. 1955. Tissue fractionation studies. 6. Intracellular distribution patterns of enzymes in rat-liver tissue. Biochem. J. 60:604-617.

20. Dupourque, D., and F. Kern. 1969. Cytoplasmic and mitochondrial malate dehydrogenase from beef kidney. Methods Enzymol. 13:116-122.

21. Leighton, F., B. Poole, H. Beaufay, P. Baudhuin, J. W. Coffey, S. Fowler, and C. DeDuve. 1968. The large scale preparation of peroxisomes, mitochondria, and lysosomes from the livers of rats injected with Triton WR-1339. J. Cell Biol. 37:482-513.

22. Reeves, W. J., and G. M. Fimognari. 1966. Lactic dehydrogenase: heart (H4). Methods Enzymol. 9:288-294.

23. 1973. Analytical methods for atomic absorption spectroscopy using the HGA graphite furnace. Perkin-Elmer Corp., Norwalk, CT.

24. Peters, T. J., M. Miller, and C. de Duve. 1972. Lysosomes of the arterial wall. I. Isolation and subcellular fractionation of cells from normal rabbit aorta. J. Exp. Med. 136:1117-1139. 
25. Beaufay, H., A. Amar-Costesec, E. Feytmans, D. Thines-Sempoux, U. Wibo, M. Robbi, and J. Berthet. 1974. Analytical study of microsomes and isolated subcellular membranes from rat livers. I. Biochemical methods. J. Cell Biol. 61:188-200.

26. Lowry, O. H., N. F. Rosebrough, A. L. Farr, and R. J. Randall. 1951. Protein measurement with the Folin phenol reagent. J. Biol. Chem. 193:265-275.

27. Leuenberger, P. M., and A. B. Novikoff. 1975. Studies on microperoxisomes. VII. Pigment epithelial cells and other cell types in the retina of rodents. J. Cell Biol. 65:324-334.

28. Spurr, A. R. 1969. A low viscosity epoxy embedding medium for electron microscopy. J. Ultrastruct. Res. 26:31-42.

29. McNary, W. F. 1963. Intrahepatic and intracellular distribu- tion of copper following chronic administration of the metal in the diet. Anat. Rec. 146:193-199.

30. Goldfischer, S. 1967. Demonstration of copper and acid phosphatase activity in hepatocyte lysosomes in experimental copper toxicity. Nature (Lond.). 215:74-75.

31. Hazelrig, J. B., C. A. Owen, Jr., and E. Ackerman. 1966. A mathematical model for copper metabolism and its relation to Wilson's disease. Am. J. Physiol. 211:1075-1081.

32. Barka, T., P. J. Scheuer, F. Schaffner, and H. Popper. 1964. Structural changes of liver cells in copper intoxication. Arch. Pathol. 78:331-349.

33. Farrer, P., and S. P. Mistilis. 1967. Absorption of exogenous and endogenous biliary copper in the rat. Nature (Lond.). 213:291292. 